$\underline{\text { Reports }}$

\title{
This disease is "not for hospital": myths and misconceptions about cancers in Northern Nigeria
}

\author{
Ahmed M Sarki', Babangida L Roni ${ }^{2}$ \\ 1 School of Nursing and Midwifery, Aga Khan University, Kampala, Uganda, ${ }^{2}$ Ministry of Health, Jigawa State, Nigeria \\ Keywords: global health \\ https://doi.org/10.29392/joghr.3.e2019070
}

\section{Journal of Global Health Reports}

Vol. 3, 2019

\begin{abstract}
Cancers are one of the major chronic diseases in Nigeria, with over 100,000 new cases and 70,000 cancer deaths recorded annually. Notwithstanding the public health significance of cancers in Nigeria, there is a dearth of evidence relating to cancers in the country, with most of the few available studies conducted in the Southern regions. This paper aimed to highlight some longstanding myths and misconceptions about cancers in the Northern Nigerian region. We consulted key stakeholders including individuals, local leaders, traditional medicine practitioners, and healthcare professionals. The most common myths and misconceptions about cancers in Northern Nigeria include the following: people get cancers from mystical sources originating in the forests or bush; western medication or hospital treatment worsens cancers; and, witchcraft can be used to transmit cancers to people. Understanding the traditional beliefs and local perceptions of non-communicable diseases is invaluable for informing sustainable and effective interventions. Thus, our paper will be useful for epidemiological, anthropological, and social research into effective preventive measures for cancers in Northern Nigeria and other regions with similar entrenched traditional beliefs about cancers.
\end{abstract}

Cancers are a global public health issue, and are responsible for 1 in 6 deaths worldwide. ${ }^{1}$ Low- and middle-income countries (LMICs) experience a disproportionate burden of cancer deaths (nearly $70 \%$ of all cancer deaths). Common cancers documented in LMICs include lung, liver, stomach, colorectal, esophagus, prostate, breast, and cervical cancers. ${ }^{1,2}$ Despite the huge burden of cancer deaths in LMICs, only $20 \%$ of LMICs have the essential data needed to formulate and implement cancer-related policies. ${ }^{2}$

In 2008, around 700,000 cancer cases and 500,000 cancer deaths were recorded in Africa. ${ }^{3}$ These figures were reported to have doubled by 2015 , and existing evidence suggests that cancer deaths in Africa will continue to increase annually over the next decade. ${ }^{4}$ The increasing trends of cancer cases and deaths in Africa are attributed to a rise in middle-class populations, increased life expectancy, and modified lifestyles (e.g., change in dietary patterns, harmful tobacco and alcohol use). ${ }^{2,3}$ African countries are also witnessing increased non-communicable diseases (NCDs) and associated risk factors, including cancers, cardiovascular diseases, hypertension, and stroke. ${ }^{4,5}$

Like many other LMICs, Nigeria is facing a double burden of diseases attributable to ongoing epidemiological and nutritional transitions, rapid population ageing, and changing lifestyles. ${ }^{6}$ Cancers are among the major causes of death and disability-adjusted life years in Nigeria. Recent estimates indicate the country records approximately 102,000 new cancer cases and over 70,000 cancer deaths annually. 6,7 Cancers of the breast, cervix, liver, prostate, bowel and colon are common cancers reported in Nigeria; however, breast and cervical cancers account for nearly half of all cancer deaths. ${ }^{7}$ A major challenge highlighted by the Federal Ministry of Health of Nigeria (FMOH) is the mortalityto-incidence ratio of cancers in Nigeria compared with other countries. ${ }^{6}$ For example, in Nigeria, half of breast cancer cases result in death compared with 1 in 5 in the United States. ${ }^{7}$ There is a dearth of evidence relating to cancers in Nigeria, with most of the few available studies conducted in the Southern regions. This Viewpoint aimed to highlight some longstanding myths and misconceptions about cancers in the Northern Nigerian region.

Northern Nigeria comprises 19 states (Figure 1) divided into three geo-political zones (North-West, North-Central, and North-East). Estimates from the last census (conducted in 2006) indicated Northern Nigeria has approximately 53\% of the country's total population. This region is characterized by poor health indices, low socioeconomic status, and the highest number of deaths and diseases compared with the Southern regions of Nigeria. ${ }^{8}$

\section{MYTHS AND MISCONCEPTIONS}

Prior to compiling information for this Viewpoint, the authors conducted a comprehensive consultation of key stakeholders including individuals, local leaders, traditional medicine practitioners, and healthcare professionals. To the best of our knowledge, the following are the most prominent myths and misconceptions about cancers from the Northern region of Nigeria. 


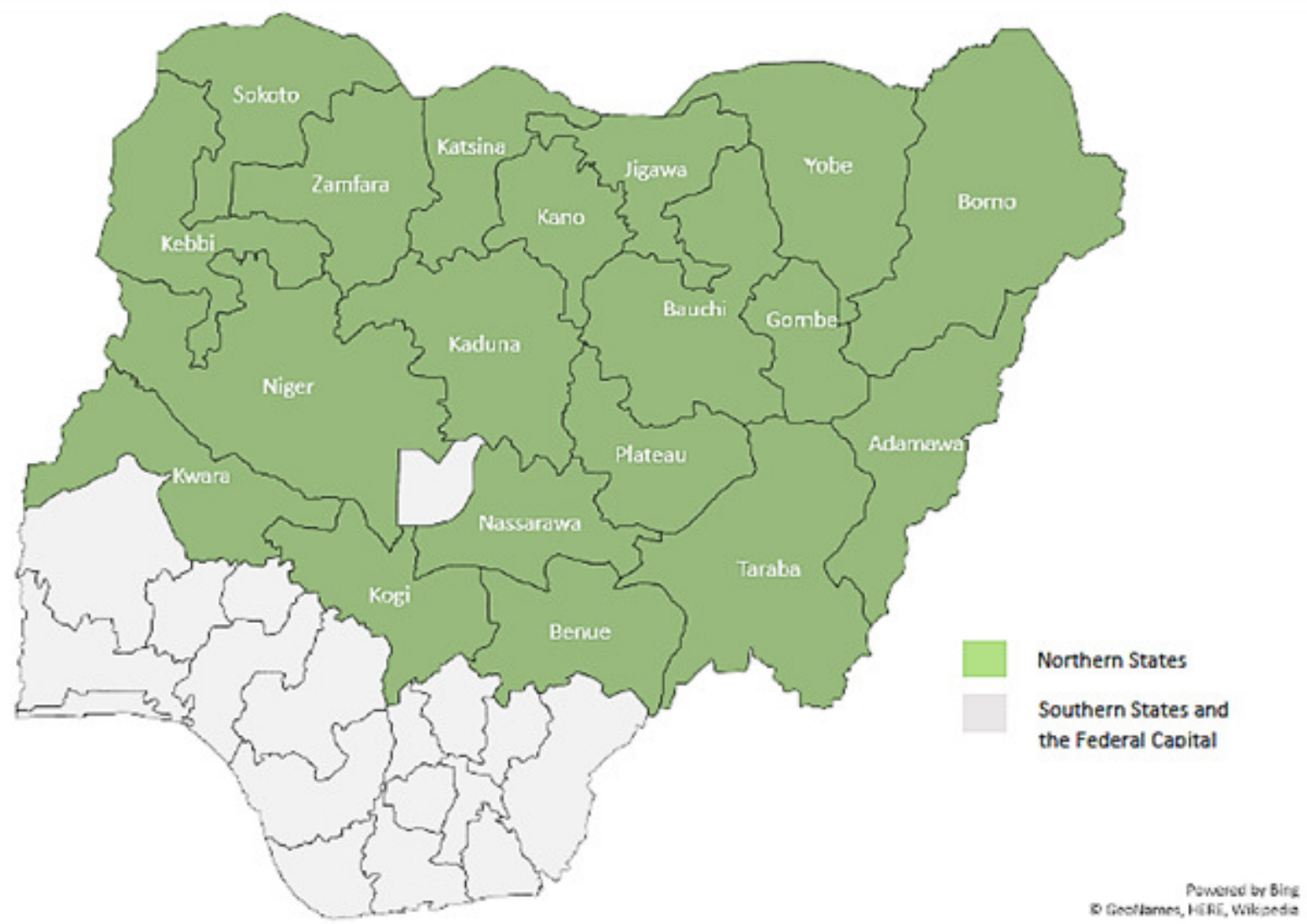

\section{Figure 1}

Map of Nigeria showing the 19 Northern states.

JEJI

A common and long-held myth about cancer in Northern Nigeria is that people get cancers from mystical sources originating in the forests or bush, which translates as "jeji" or "daji" in the Hausa language (the predominant language in the region). It is believed that when mystical forces from the forests or bush "bedevil" someone, that person gets jeji. Therefore, the only remedy is approaching religious leaders for prayers in tandem with visiting traditional herbalists, who use local herbs, shrubs, or a cocktail of both. In some communities, people do not even mention jeji when describing the illness, for fear of being the next victim or perhaps offending the perceived mystical forces.

\section{HOSPITAL TREATMENT WORSENS CANCERS}

Another popular misconception is that Western medication or hospital treatment worsens cancers, and patients are likely to die prematurely when taken to hospital. Therefore, some communities in Northern Nigeria are against taking patients with cancer to hospital and reluctant to seek hospital-treatment for their loved ones; instead, they turn to trado-religious therapy. A perturbing aspect is that some educated individuals in the region also subscribe to this misconception, which shows how deeply rooted such beliefs are. The few families that take their loved ones to hospital do so when the cancers are at an advanced stage, and tradoreligious remedies have proven ineffective.
Academics, researchers, and development workers familiar with belief systems in Northern Nigeria may not find this situation surprising. This is because the population of Northern Nigeria, including the political class, often has reservations about/mistrust of Western medications, treatments, and healthcare interventions. A classic example is the suspension of immunization activities that occurred in several Northern states from July 2003 to April 2004. This was triggered by suspicion that polio vaccines contained antifertility agents, and were used to sterilize young Muslim girls in order to depopulate the Northern region. ${ }^{9}$ This suspension led to a global health crisis-an outbreak of poliomyelitis in about 20 polio-free countries across parts of Africa and other world regions-that necessitated global coordination of efforts across multilateral agencies and governments, and cost more than US $\$ 500$ million. $^{9}$

\section{WITCHCRAFT}

Deeply-rooted traditional and cultural beliefs in parts of Nigeria mean that many diseases and health issues are perceived to be caused by witches and witchcraft. ${ }^{10}$ This led to the persecution of and false allegations about many innocent people in communities across Nigeria, including children. The misconception that cancer affects people through witchcraft remains popular in some communities across Northern Nigeria. It is also important to note that many people who believe witchcraft mediates disease causation 
do not seek treatment at hospitals or health facilities. Some communities believe that public "naming and shaming" of the perceived witch remedies the bewitched person's illhealth. However, many people resort to other means, including trado-religious interventions.

\section{RECOMMENDATIONS}

\section{TAILORED AWARENESS CAMPAIGNS}

Many of the myths and misconceptions about cancers in Northern Nigeria are associated with traditional beliefs and lower socioeconomic status (illiteracy and poverty). Therefore, well-crafted, tailored health awareness and sensitization campaigns in Northern Nigeria conducted in the predominant local languages may be effective in debunking these myths and misconceptions. The present authors advocate a co-produced awareness campaign for cancers and their risk factors led by governments at all levels (federal, state, and local governments). Such campaigns should include key stakeholders such as religious and traditional leaders, health workers, civil servants, alternative medicine practitioners, and patient representatives.

\section{LEGISLATION}

There is an urgent need for effective legislation at national and state levels focused on reducing the exposure of Nigerians to carcinogens. The FMOH admits that lack of legislation addressing the risk factors for cancers (including tobacco and alcohol use, food labeling, and vaccinations) significantly reduces the likelihood of the success of cancer control. ${ }^{7}$

\section{NATIONAL SCREENING PROGRAMS AND PALLIATIVE CARE}

Nigeria does not have a well-coordinated national screening program for cancers, and it is seemingly impossible to screen for all cancers; this gap also plays a significant role in the late presentation of most patients with cancer to cancer facilities. ${ }^{6,7}$ In late stage cancer, cure may no longer be possible or treatment (e.g., surgery and radiotherapy) may not be available or affordable. The government and other actors working on cancers should facilitate the integration of routine screening for eligible cancers into existing health programs. In addition, as individuals often present to facilities with advanced-stage cancers, government and other stakeholders could consider developing frameworks for effective palliative care.

\section{EFFECTIVE CANCER REGISTRIES}

A positive development is that the number of cancer registries in Nigeria increased from three to 284 over the last decade. However, only 96 of these registries are populationbased; the remainder is hospital-based. These registries have some limitations in terms of their effectiveness, including poor data quality, ${ }^{7}$ insufficient funding for continuous and smooth operation, and limited opportunities for capacity building of registry staff. Government at all levels should increase the health budget for NCDs, and invest in providing effective cancer registries.

\section{RESEARCH}

Population-based research studies in oncology are not well developed in LMICs, including Nigeria. However, the National Cancer Control Plan 2018-2022 developed by the FMOH prioritizes improved cancer research in Nigeria over the next 5 years. ${ }^{7}$ Therefore, researchers across institutions of learning, non-governmental organizations, and thinktanks need to intensify efforts in cancer research to unravel potentially effective solutions for debunking myths and misconceptions about cancers and increasing the uptake of available services. We recommend undertaking research to understand emic and etic perspectives of cancer in Northern Nigeria.

\section{CONCLUSION}

This Viewpoint provides contextual understanding about common myths and misconceptions relating to cancers in Northern Nigeria. Concerted effort through tailored awareness campaigns, effective legislation, screening programs, palliative care, cancer registries, and research is required to debunk the myths and misconceptions about cancers in the 19 Northern Nigerian states, and Nigeria as a whole. Finally, this Viewpoint may be useful to inform epidemiological, anthropological, and social research into effective preventive measures for cancers in Northern Nigeria and other regions with similar entrenched traditional and cultural beliefs about cancers.

\section{ACKNOWLEDGEMENTS}

The authors would like to thank Dr Zaharaddin, Branch Chairman of the National Association of Nigerian Traditional Medicine Practitioners, Jigawa State, for his invaluable insights and contributions. The authors would also like to acknowledge Tayreez Mushani, University Health Network, Ontario, Canada, for her inspiration. The authors dedicate this article to the memory of Mohammed Ahmed and all those who lost their fight with cancers in Northern Nigeria because of myths and misconceptions surrounding the disease in the region.

\section{FUNDING}

None.

\section{COMPETING INTERESTS}

The authors have completed the Unified Competing Interest form available from http://www.icmje.org/conflicts-of-interest/ and declare no competing interests. 


\section{CORRESPONDENCE TO:}

Ahmed M. Sarki, MPH, PhD

School of Nursing and Midwifery

Aga Khan University

Plot 9/12 Colonel Muammar Gaddafi Road
PO Box 8842

Kampala

Uganda

ahmed.sarki@aku.edu 


\section{REFERENCES}

1. World Health Organization. 10 facts about cancer 2017. Accessed April 6, 2017. https://www.who.int/fea tures/factfiles/cancer/en/

2. World Health Organization Regional Office for Africa. Cancer. WHO Regional Office for Africa; 2017.

3. Jemal A, Bray F, Forman D, et al. Cancer burden in Africa and opportunities for prevention. Cancer. 2012;118(18):4372-4384. doi:10.1002/cncr.27410

4. Stefan DC. Cancer care in Africa: An overview of resources. J Glob Oncol. 2015;1(1):30-36. doi:10.1200/ jgo.2015.000406

5. Olaleye O, Ekrikpo U. Epidemiology of Cancers in Sub-Saharan Africa. In: Adedeji O, ed. Cancer in SubSaharan Africa. Springer; 2017:3-19. doi:10.1007/97 8-3-319-52554-9 1
6. International Agency for Research on Cancer. Nigeria - Global Cancer Observatory. IARC; 2019.

7. Federal Ministry of Health. Nigeria: National Cancer Control Plan 2018-2022. FMoH; 2018.

8. National Population Commission (NPC) \& ICF International. Nigeria 2013 Demographic and Health Survey. NPC and ICF International; 2014.

9. Kaufmann JR, Feldbaum H. Diplomacy and the polio immunization boycott in Northern Nigeria. Health Aff (Millwood). 2009;28(4):1091-1101. doi:10.1 377/hlthaff.28.4.1091

10. Archibong EP, Enang EE, Bassey GE. Witchcraft Beliefs In Diseases Causation And Health - Seeking Behaviour In Pregnancy Of Women In Calabar South Nigeria. IOSR Journal of Humanities and Social Science. 2017;22(06):24-28. doi:10.9790/0837-2206042428 